\title{
Case Study on Numerical Calculation of a Disc Bush in the Disc Harrow in the Welding Version
}

\author{
Pawel LONKWIC*, Ireneusz USYDUS*, Arkadiusz Tofil*, Tomasz KRAKOWSKI**, \\ Hubert RUTA**, Daniel PIENIAK*** \\ *The State School of Higher Education, The Institute of Technical Sciences and Aviation, Pocztowa Street 54, 22-100 \\ Chetm,Poland,E-mail:plonkwic@pwsz.chelm.pl; iusydus@pwsz.chelm.pl; atofil@pwsz.chelm.pl \\ **Faculty of Mechanical Engineering and Robotics, AGH University of Science and Technology, Adama Mickiewicza Ave. \\ 30 (B2-p115),30-059 Kraków, Poland, E-mail: krakowsk@agh.edu.pl; hubert.ruta@agh.edu.pl \\ ***Department of Mechanics and Machine Building, University of Economics and Innovations in Lublin, Projektowa 4, \\ 20-209 Lublin, Poland, E-mail: daniel.pieniak@wsei.lublin.pl \\ crossref http://dx.doi.org/10.5755/j02.mech.28233
}

\section{Introducation}

As compared to the cultivators, the disc harrows facilitate the performance of shallower stubble cultivation and mix better the stubble with the soil [1] and, thanks to cutting the harvest residues, they are less exposed to clogging. The classic disc harrows with the sections set askew to the work direction are superseded with compact disc harrows where the discs are secured individually and are set in two parallel rows. Use of the harrow after sowing enables covering the cultured seeds with a thin layer of soil [2]. An example of a disc harrow is shown in Fig. 1 [3].

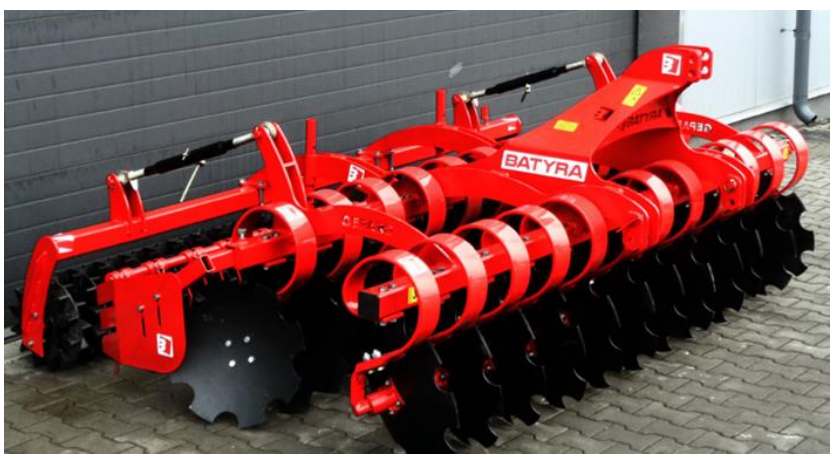

Fig. 1 Disc harrow of Henry Batyra make [3]

\section{Soil types materials and methods}

Being the units that facilitate the farmers' work, the disc harrows are exposed to various field conditions, taking into account variability of soils. Apart from variability of soils, the machine loading conditions change, and thus the loading of its executive elements such as the discs. Based on the classification of arable lands, the soils are divided into classes, depending on their valuation. The arable lands are evaluated on the basis of field examination of soil pits, with particular attention paid to such morphologic features and soil properties as: location, profile structure (soil agility and topsoil), colour, structure, granulometric composition of particular levels, permeability, hydrographic conditions, reaction, calcium content expressed as calcium or carbonate oxide and others.

The following factors impact the mechanical loading of the arable equipment:

- $\quad$ rooting remains in the soil;

- communication tunnels of the rodents;
- fossil remains in the soil;

- other.

All the mentioned factors (that do not occur simultaneously) during the steady ploughing result in temporary loading of the disc and adversely affect the entire mounting system. In this paper, the results of numerical analysis for the optimized harrow dismounting have been presented.

Determination of the structure component effort was discussed in many publications. In the publication [4], the authors described the application of numerical techniques to describe the operation of brakes in transport devices such as the personal lifts. They indicated the possibility of applying the numerical simulation based on the finite element method to simulate the complex physical phenomena. In the publication [5], the authors presented the results of computer simulation of the load-carrying structures located under the mechanical unit reducers. In the article, the authors described the application of the so-called remote load to simulate the effort and strains of the supporting structure due to loads operating at the pre-set distance. In the publications [6], the authors described the application of numerical analyses of plastic working of metals. In this publication, the authors presented the possibility of using the Simufact Forming commercial software based on the finite element method (FEM) to simulate the stepped shaft processing. The numerical analysis enabled to define changes in the machined object shape, distribution of strains and temperature as well as the changes of forces that the tool is exposed to. The numerical results proved that currently the personal computers may be used for modelling even the most difficult cases of the rolling process where the complex shapes of tools and the thermal phenomena occurring during the forming process are taken into account. The modelling of welded joints was described in the publication [7] in which the authors presented the application of the peak stress method (PSM) to estimate the stress intensity coefficients in the notch.

\section{Disc loading diagram}

The steady condition of the arable system (i.e. during movement at constant velocity) is presented in Fig. 2. In the general case, the tractor force must be bigger than the total forces loading the disc in the harrow and the resistance forces of the wheel rolling over the soil, what can be recorded as the following dependency (1): 


$$
F>\sum N+F_{o T}+F_{o B},
$$

where: $F$ is tractor force, $\mathrm{N} ; \sum N$ is total of component forces loading the discs, depending on the number of discs, $\mathrm{N} ; F_{o T}$ isresistance force of tractor wheel rolling in soil, $\mathrm{N}$; $F_{o B}$ is resistance force of harrow wheel rolling in soil, N.

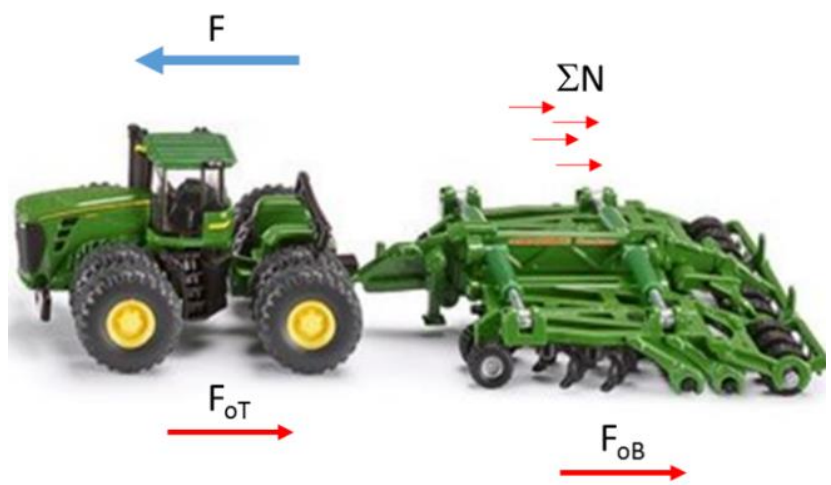

Fig. 2 General distribution of forces in arable system

The executive elements of the disc harrow are the discs whose quantity depends on the type and design of the very harrow. A single disc 1 is secured to the hub 2 via screw joints and then it is connected to the load-carrying structure 3 of the harrow. The typical disc-hub-harrow arrangement is shown in Fig. 3.

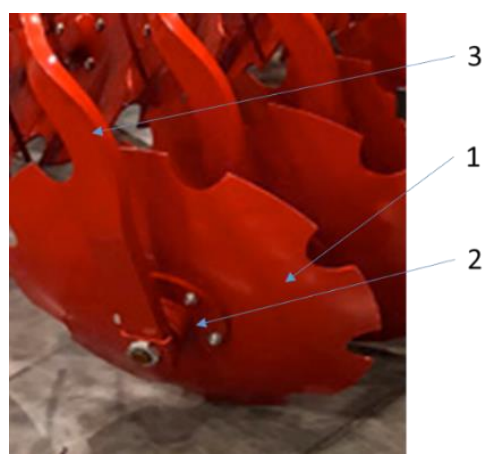

Fig. 3 Disc attachment in the harrow [3] operation:

Every disc may be loaded in two ways during its

- $\quad$ method I - loaded with constant soil pressure onto the disc surface and with constant bending moment resulting from the fixed arable system movement;

- $\quad$ method II - loaded with constant soil pressure with random hitting against the disc surface by contamination in the form of stones or others that result in temporary increase of the bending moment at the location of the bush connection to the harrow structure.

The geometry and the schematic distribution of forces and torques occurring in the disc system are shown in Fig. 4.

During the steady operation, the disc is exposed to a complex loading condition. The normal force $N$, when acting onto its surface, generates two components of force $N_{s}$ and $N_{x}$ that lead to the occurrence of the total bending moments against the hub axis. There is a correlation between the forces $N_{s}$ and $N_{x}$ taking into account the disc angle $\alpha$. The torsional moment $M_{s}$ is the result of friction force acting onto the disc surface and making it rotate during the arable movement. In the normal conditions of work, the torsional moment value may be ignored as this is the bearingmounted system and the moment value depends on the technical condition of the bearing-mounted system. The torsional moment value shall be important in the situation when the bearing-mounted system gets excessively contaminated.

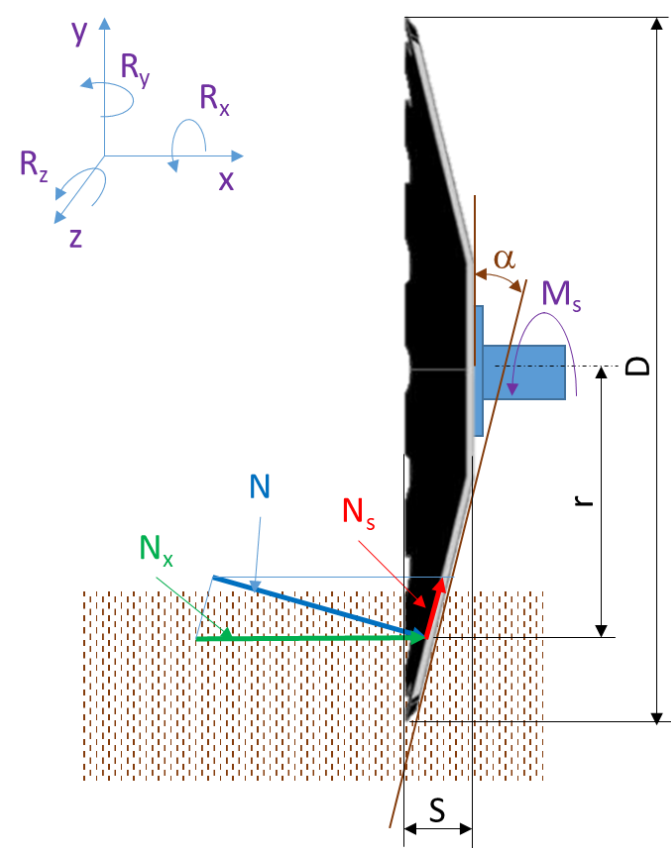

Fig. 4 Model of disc with loading

As mentioned before, the manner of bush mounting enables its rotation in the system of bearings. Thus, due to such mounting manner, the bush receives 5 stages of freedom, what can be recorded as $U_{x}=U_{y}=U_{z}=R_{y}=R_{z}=0$. The disc is secured by means of 4 bolts M10 to the bush hub and thanks to this, the torsional moment does not load the bush structure.

\section{Hub optimization}

The main assumption of the hub optimization process is to replace the accessible commercial elements (Fig. 5) by a possibility of manufacturing the hub from the generally available materials. Such an approach has the following positive aspects:

- reduction of the number of wastes returned to the institutions involved in reprocessing of the metal wastes;

- $\quad$ increase of the company production assortment;

- increase of the assortment of machines available in the market;

- decrease of the unit price of the manufactured detail parts as compared to the purchase price.

The bush shown in Fig. 5 is made of a monolithic casing with the bearings inside it. The bearings contain an axle by means of which the mating rotary parts are fixed. In the model presented in this study, the attention is focused on the optimization of the casing as a welded structure. Therefore, the bearing with its axle on which the mating rotary elements are fastened has been ignored.

To comply with the above-mentioned assumptions, the $3 \mathrm{D}$ hub model was developed, being the combination of the element in the form of a flange 1 and a bearing bush 2; see Fig. 6. 


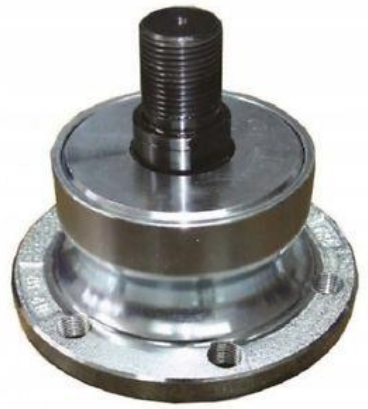

Fig. 5 Bearing hub dedicated to the agricultural sector [8]

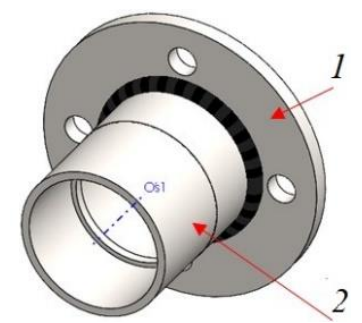

Fig. 6 Numerical model of bearing bush

Based on the numerical model developed, the production documentation was elaborated that also allows for the implementation of the automatic welding process of the bush components. To this aim, the dedicated welding machine was developed the model 3D of which is shown in Fig. 7, a, and its physical fabrication - in Fig. 7, b.

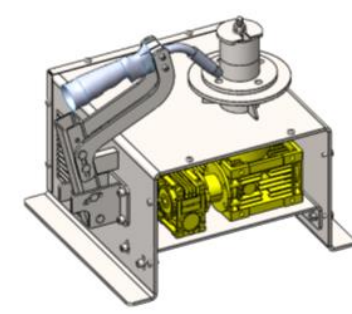

a

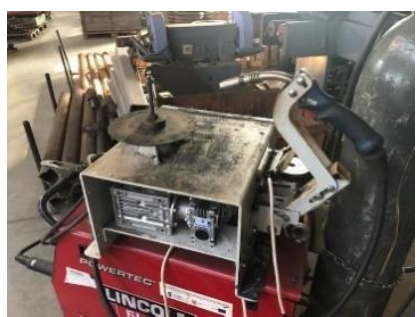

$\mathrm{b}$
Fig. 7 Dedicated welding machine: a) model 3D, b) physical model

For quick arming of the device with the detail parts to be welded, a cylindrical matrix was used to fix the bush in relation to the cover, maintaining their mutual concentricity, and the quickest possible way of fixing was obtained by using a cut pressure pad (Fig. 7). The use of a washer in this form gave the machine operator the possibility to quickly dismantle the welded bush without having to unscrew the nut completely. Thanks to the use of a welding clamp, the operator did not affect the welding speed in any way and thus the quality of the weld. Shortening of the welding operation time was achieved by using a gear-motor with a single-phase motor. Starting of the device (rotary motion of welded parts and arc ignition) was performed by means of a tilting bracket with a fixed welding handle. When the welding process is completed, the deflection of the welding handle caused the welding process to end and the rotating bush to stop. Thanks to the detailed numerical model of the welding device, a small and compact device was obtained and the design work was done using the SolidWORKS software.

The assumptions enabled to obtain the detail part shown in Fig. 8.

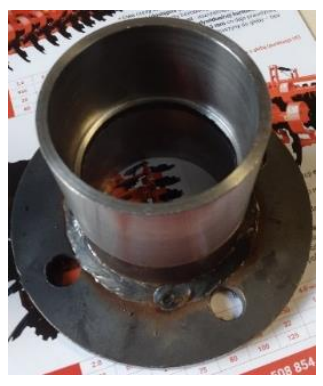

a

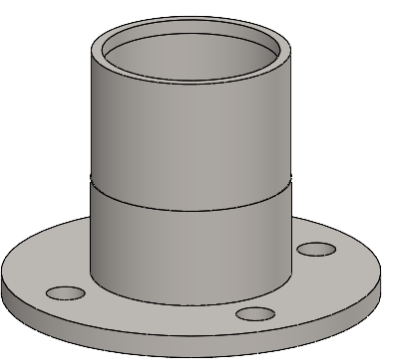

b
Fig. 8 Hub bush a) in acc; b) with the numerical model developed

\section{Numerical simulation}

The last stage of the study consisted in the accomplishment of numerical simulations to define the life of the developed bush and to confirm the numerical results on the stand equipped with the testing machine. For this purpose, the simplified manner of the bush loading was developed (shown in Fig. 9) consisting in the generation of the bending moment that loads the bush flange and, also, the flange-tobush weld. The 3D modelling and numerical simulations were performed using the SolidWORKS and SolidWORKS Simulation program.

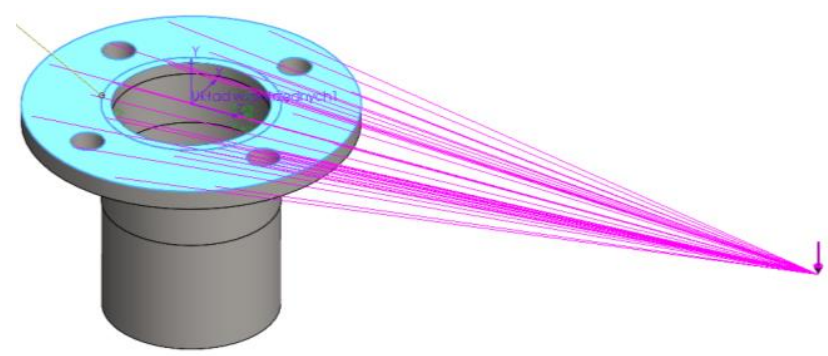

Fig. 9 Diagram of loading the bush with the finite element grid

For the bush model loading, the remote load mounted directly to the bush flange was accepted, while the mounting was applied to the surface with which the ball bearings (green marked) cooperate. As the available publications miss the information concerning the load values of the system analysed, it was agreed with the company financing the presented case that the load value $F$ of the disc would amount to $2300 \mathrm{~N}$. Fig. 10 shows the discrete model of the bush with the FEM grid applied.

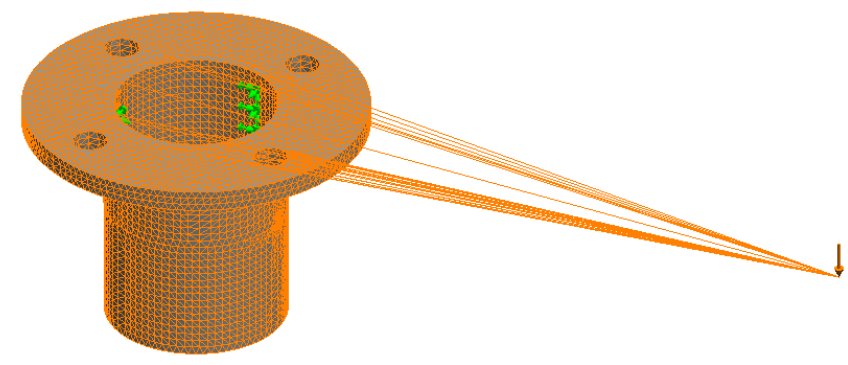

Fig. 10 Discrete bush model

The bush model was discretized using the highquality solid mesh with the $3 \mathrm{~mm}$ elements and the tolerance of $0.15 \mathrm{~mm}$ with Jacobian points placed in the nodes. The weld was not placed in the 3D model of the bush due to lack 
of simulation possibilities in the applied software, and the results were based on the stress values at the contact edge of the bearing bush with the flange. A global contact was used to prepare the numeric model, and a non-penetration contact was used at the point of contact between the bearing bush and the cover.

It was accepted for the numerical simulation that the bush shall be made of S235 grade material the strength parameters of which are presented in Table 1.

Table 1

Compilation of mechanical properties of the S235 material [9]

\begin{tabular}{|c|c|c|c|}
\hline Description & Symbol & Value & Unit \\
\hline Young's modulus & $E$ & 210000 & $\mathrm{~N} / \mathrm{mm}^{2}$ \\
\hline Poisson's ratio & $v$ & 0,28 & - \\
\hline Mass density & $\rho$ & 7800 & $\mathrm{~kg} / \mathrm{m}^{3}$ \\
\hline Tensile strength & $R_{m}$ & 355 & $\mathrm{MPa}$ \\
\hline Yield strength & $R_{e}$ & 275 & $\mathrm{MPa}$ \\
\hline
\end{tabular}

The bush effort simulation was conducted in the linear-elastic scope of the material. The bush was secured to the internal surface on which the bearings are mounted, what allowed receiving 3 displacement stages of freedom $U_{x}=U_{y}=U_{z}=0$ and two rotation stages $R_{x}=R_{y}=0$. Fig. 11 shows the results of numerical simulation of stresses and displacements of the bush elements. Such assumptions allowed obtaining the stresses in the bush at the $125 \mathrm{MPa}$ level, as shown in Figs. 11 and 12.

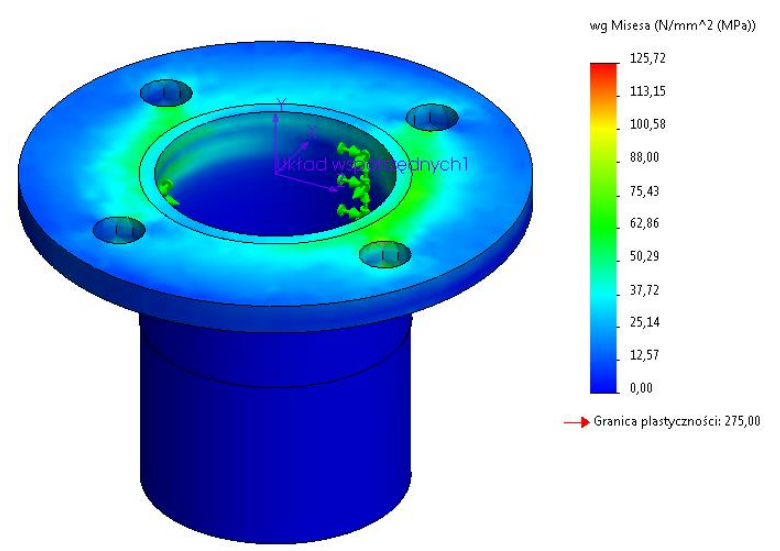

a

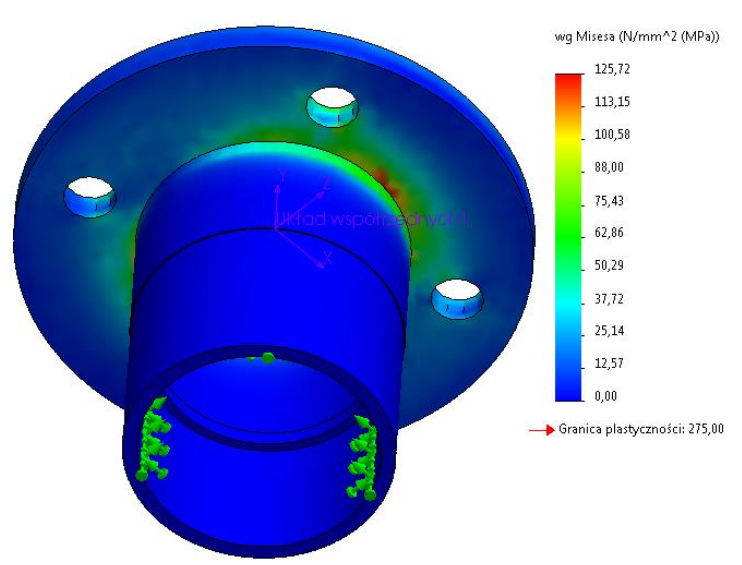

b

Fig. 11 Bush effort for the load of $2300 \mathrm{~N}$ : a) isometric view, b) isometric view from bush bottom
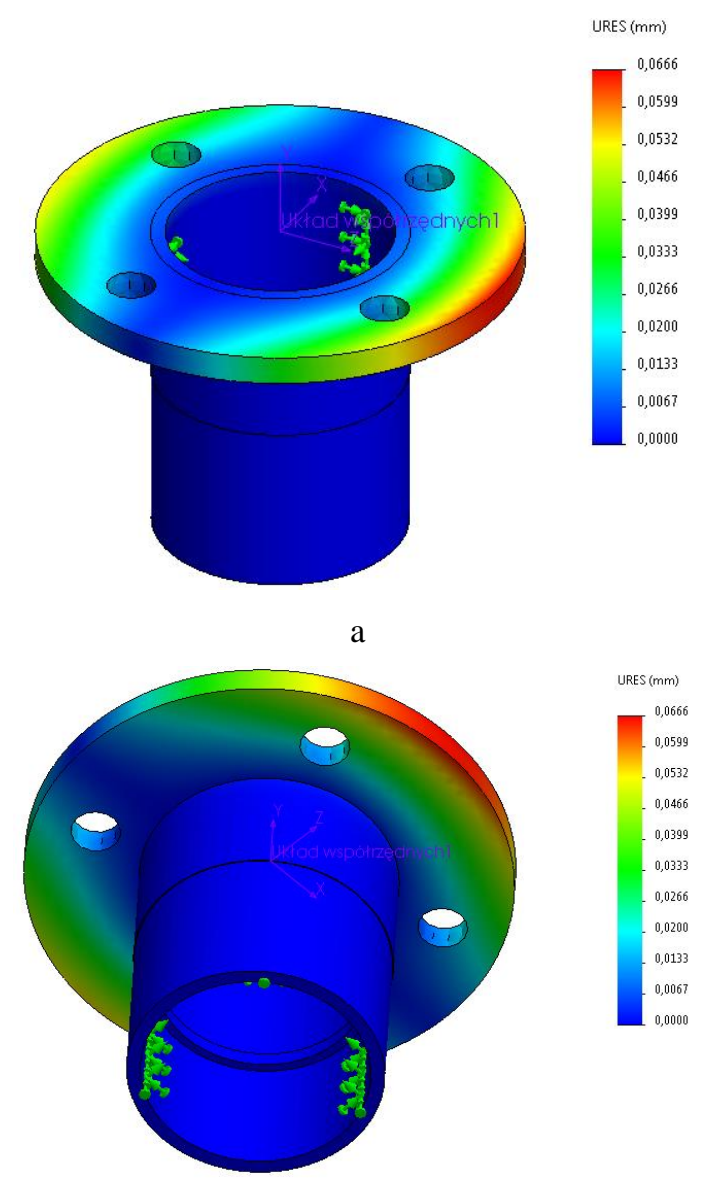

b

Fig. 12 Displacement of bush components: a) isometric view, b) isometric view from bush bottom

The numerical simulation presented above allowed performing the fatigue simulation of the bush, as shown in Fig. 13. To present the locations of the lowest durability factor, 1100 cycles with the loading of multiplied value up to $23000 \mathrm{~N}$ in the zero-pulsating system were accepted for the simulation. Acceptance of such a loading diagram in accordance with the assumptions simulated the occurrence of temporary increases of the bush loads due to, for example, a stone in the soil being ploughed that the harrow disk drove onto.

Based on the accomplished numerical simulations of the bush effort, two major areas can be observed. The first effort area shown in Fig. 12, a covers the upper surface of the bush flange, where the stresses $\sigma_{z g}$ are at the level of $75 \mathrm{MPa}$. The second area is shown in Fig. 1, b and covers the lower area of the flange where the maximum stresses $\sigma_{z d}$ of $125 \mathrm{MPa}$ are generated. The value of the flange effort from the bottom is the result of bending the flange against the bush and thus generation of pressure by the flange edge onto the bush surfaces. The bush loading condition shows the propagation of the flange movements at the level of $U_{y}=0,06 \mathrm{~mm}$ that is compliant with the assumed loading direction. The stresses at the level of $\sigma_{z g}=125 \mathrm{MPa}$ as compared to the yield point of the accepted material allow obtaining the safety factor at the level of 2.2.

Fig. 13 shows the fatigue simulation results. Fig. 13, a shows the durability distribution of the bush analysed. It turns out from the presented map that, in relation to 1 million of cycles, upon accomplishment of 6080 cycles, 
the micro cracks reducing the bush life may occur in the locations marked red. Fig. 13, b shows the damage locations with the probability of $18 \%$. This means that the damage may occur first on the lower surface of the flange at the interface with the cylindrical surface of the bush after reaching the maximum number of cycles.

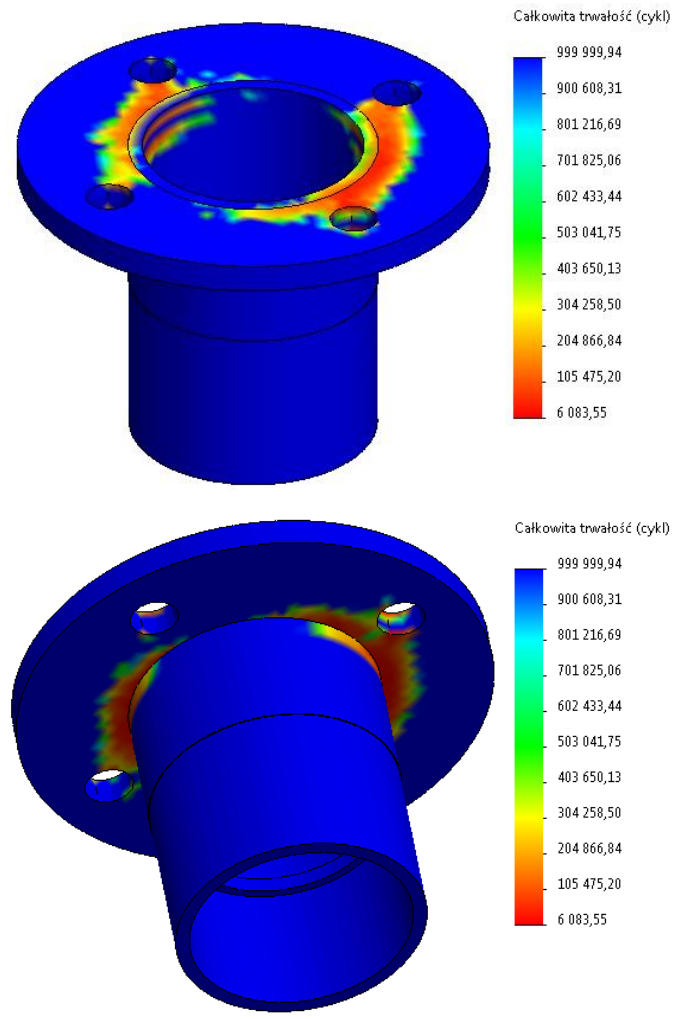

a
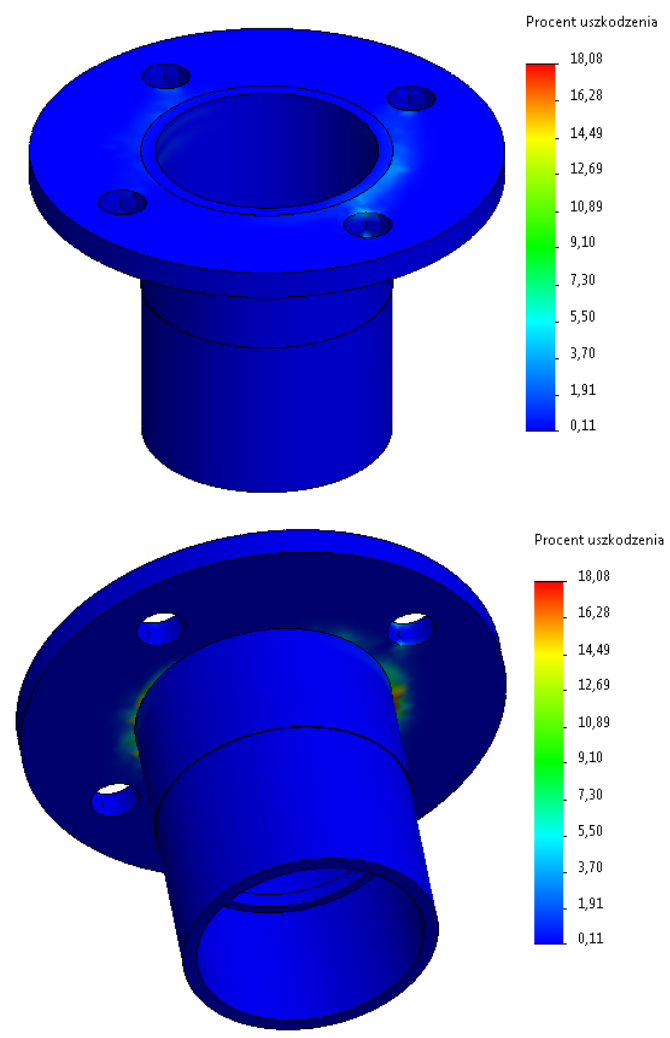

b

Fig. 13 Results of fatigue simulation: a) durability, b) damage percentage value

\section{Load simulation on the test stand}

The simulation tests accomplished on the basis of the developed spatial model of the bush were verified on the laboratory stand by means of the testing machine HT-2402s of Hung-Ta make. To perform the laboratory tests, the bush was provided with an arm by means of which it was possible to generate the bending moment. The stand is shown in Fig. 14

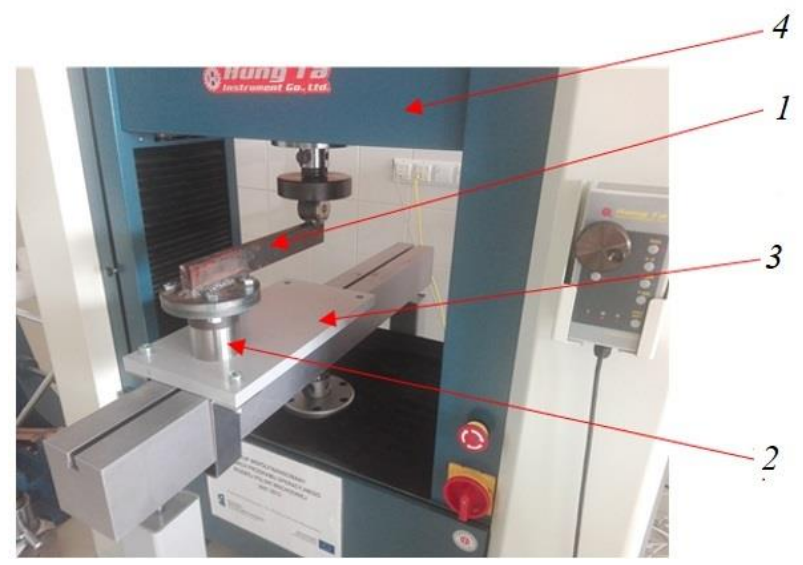

Fig. 14 Laboratory test stand for the bush durability assessment: 1 - arm, 2 - bush, 3 - intermediate panel, 4 - testing machine

The simulation test validation process consisted in generating the load $F$ of $23000 \mathrm{~N}$ by the head of the machine 4 via the arm 1 , holding such a load for $2 \mathrm{~s}$, and then load relief of the arm down to $15000 \mathrm{~N}$. During the laboratory tests, altogether 15 iterations were made, each of 1100 cycles. Fig. 15 shows the average value of the cycle calculated from the following dependency (2).

$$
\bar{x}=\sum_{i=1}^{15} F
$$

where: $F$ is bending force value, $\mathrm{N} ; \bar{x}$ - average value.

Fig. 15 shows the hysteresis loop recorded during fatigue cycles performed on the testing machine. Within the deflection in the $U_{y}$ axis from 0 to $0.98 \mathrm{~mm}$, the force value was increasing in the manner close to a hyperbola. Such a condition resulted in elimination of clearances that occurred on the stand and obtaining the initial stress in the system tested. In this scope, the value of force $\mathrm{F}$ loading the tested system reached from 0 to $1.45 \times 10^{3} \mathrm{~N}$. The further increment of the cyclic deflection resulted in obtaining the load value from $1.45 \times 10^{3}$ to $2.3 \times 10^{3} \mathrm{~N}$. Periodicity of iterations was reached within approx. $2.5 \mathrm{~s}$.

\section{Non-destructive testing of welded joint in the bush Numerical simulation}

The conducted laboratory tests didn't reveal any noncompliance of the welded joint on the flange and the bush. Thus, the additional two non-destructive tests of the welded joint were performed. During the first stage, the penetrant inspection was conducted accordance with the standard [10-12]. To this aim, the bush surfaces were identified, as shown in Fig. 16. The surface identified as 1 corresponded to the surface opposite the bush-loading moment 
shown in Fig. 9. Also, the surface identified as 3 corresponded to the surface on the side of the bush-loading moment. The surfaces 2 and 4 were the surfaces located on two sides of the bush-loading moment. The penetrant inspection was performed by the colour technique with the 20 -minute penetrant dwell time at ambient temperature of $25^{\circ} \mathrm{C}$. The laboratory illumination was $608 \mathrm{~lx}$. The nonconformities were developed after 10 and 30 minutes.

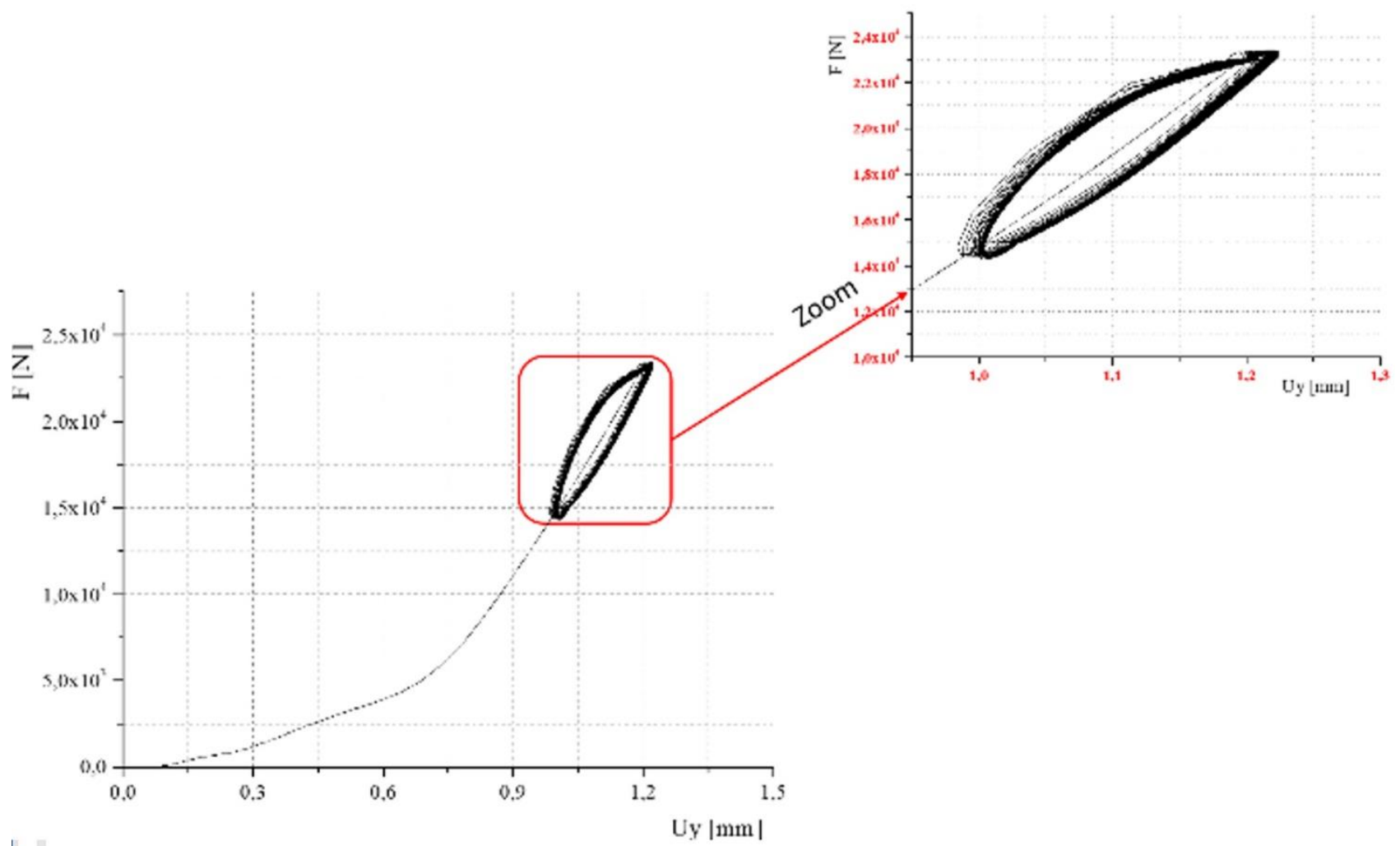

Fig. 15 Bush deflection hysteresis loop

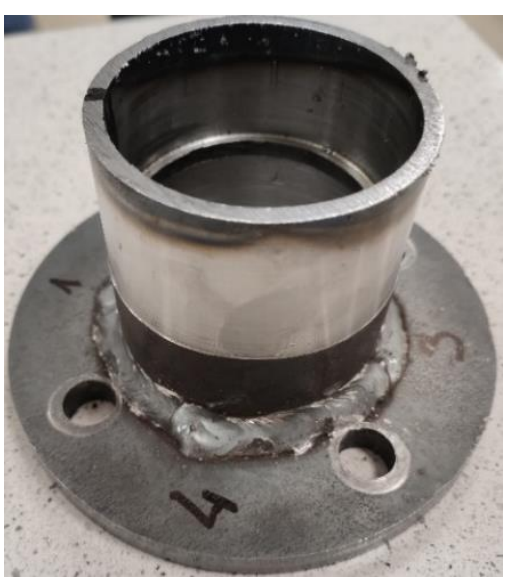

Fig. 16 Bush prepared for penetrant inspection with surfaces identified

During the first stage of tests, the joint was cleaned of surface contamination and then the BDR-L penetrant of $\mathrm{H}$ Klumpf make was applied. An example of the tested bush with the penetrant applied is shown in Fig. 17, a.

After 20 minutes, the penetrant-coated area was cleaned using the BRE remover of $\mathrm{H}$ Klumpf make, and then the developer was applied, as shown in Fig. 17, b.

Upon the accomplishment of penetrant tests, the joint cross-section was inspected. The sample preparation consisted in cutting it in the plane where the bush-loading moment was applied, as shown in Fig. 9. After cutting, it was submitted to the smoothing process on the metallographic polisher using the 80, 100, 180, 220 and 800-grit abrasive paper and then to the process of polishing by means of a disc with felt and low-abrasive paste. The sample prepared for visual inspection is shown in Fig. 18.

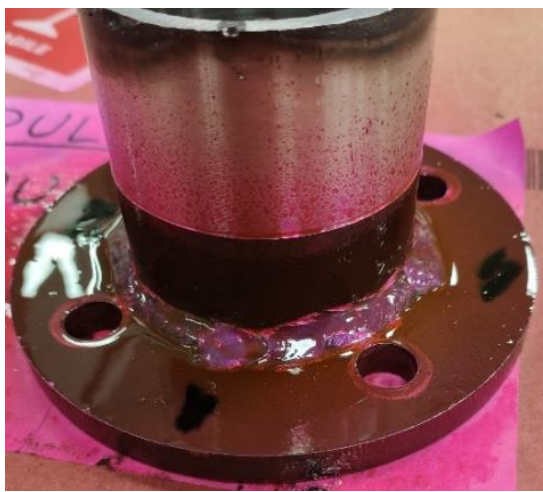

a

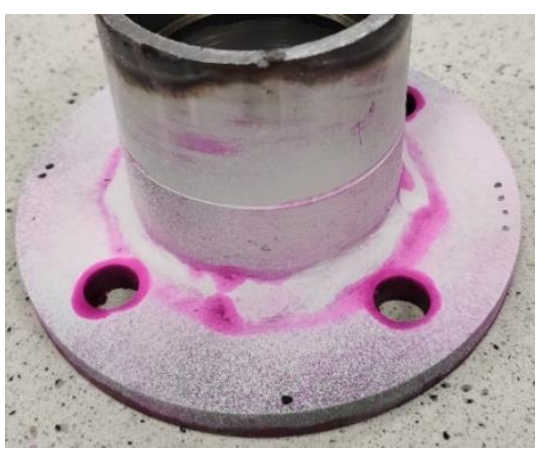

b

Fig. 17 Bush prepared with: a) penetrant applied, b) developer applied 


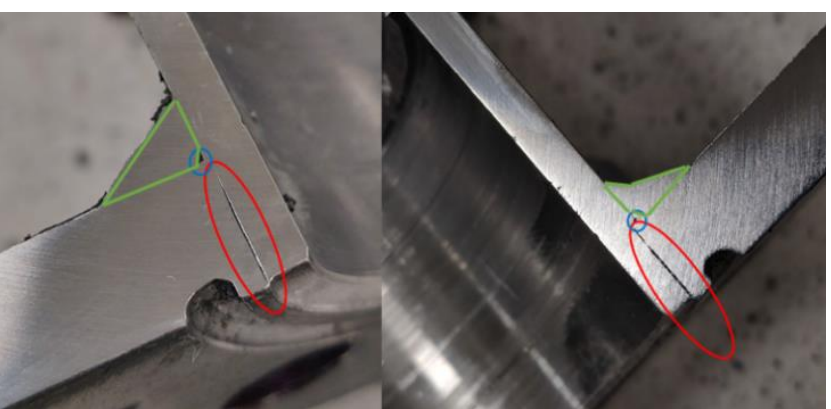

a

b

Fig. 18 Half of the bush with visible joint and gap between bush and flange

When the polishing process was completed, the sample clearly revealed: a gap between the bush and the flange (marked red), a joint (green colour) and a clear lack of joint penetration (blue colour). While analysing Fig. 18, it can be noticed that the joint cross-section is not uniform due to manual welding and this has an impact onto the stress concentration in the area of its occurrence. Then, the sample was etched in $6 \%$ nital. The observations were made at the magnification of 50 times, using the Nikon MA100 microscope.

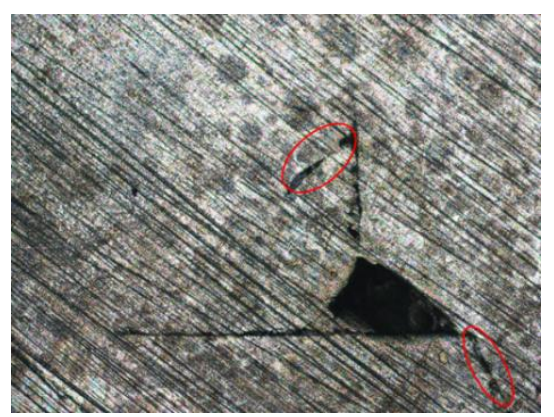

a

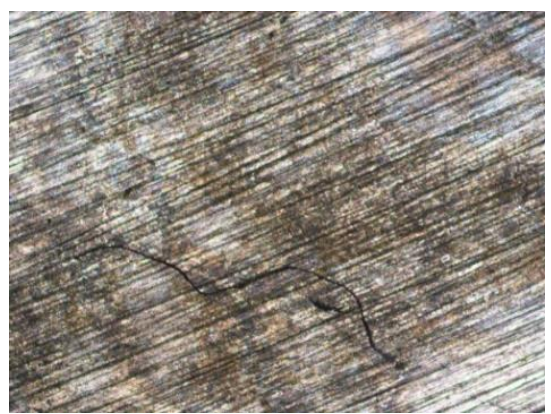

Fig. 19 Defects in form of micro cracks occurring at the joint

As a result of the studies aiming at a wider quality analysis of the joints made, the micro cracks were detected in the joints and indicated in Fig. 19. The defects shown in Fig. 20 may indicate the incorrect engineering conditions of the welded joint.

\section{Discussion on the obtained results}

The accomplished laboratory tests confirmed the numerical simulation results as compared to the quality assessment. The quantitative assessment was made on the basis of non-destructive and visual inspections. The abovementioned tests were performed on a manually welded sample without using the semi-automatic welder described at the beginning. Thus, Fig. 20 shows two locations marked yellow (the beginning and the end of the welding process), which indicate the halfway welding of the sample.

Such locations clearly show the engineering notch being the source of stress concentration and, as a result, cracking of the joint. The occurrence of the mentioned notch is the effect of local undercuts of negligible sizes that had appeared during the welding process. Pink envelopes around the holes indicate machining that resulted in micro notches.

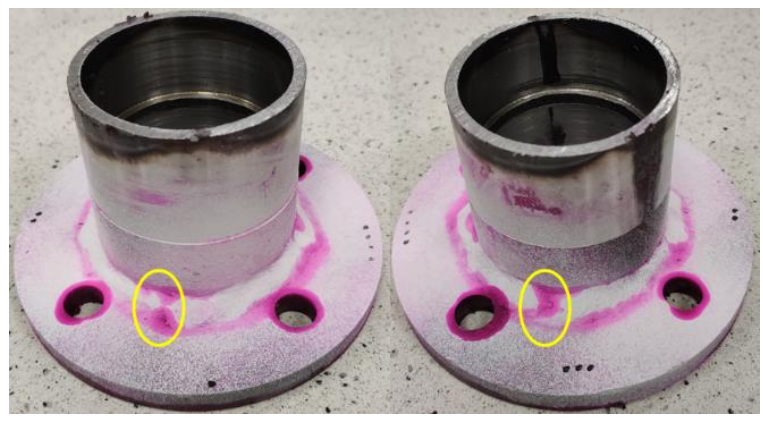

a

$\mathrm{b}$

Fig. 20 Bushes with visible beginning and end of the weld

Such locations clearly show the engineering notch being the source of stress concentration and, as a result, cracking of the joint. The occurrence of the mentioned notch is the effect of local undercuts of negligible sizes that had appeared during the welding process. Pink envelopes around the holes indicate machining that resulted in micro notches.

The occurrence of the mentioned notches is a result of the lack of uniform cross-section of the weld along its entire circumference, which is shown in Fig. 21.

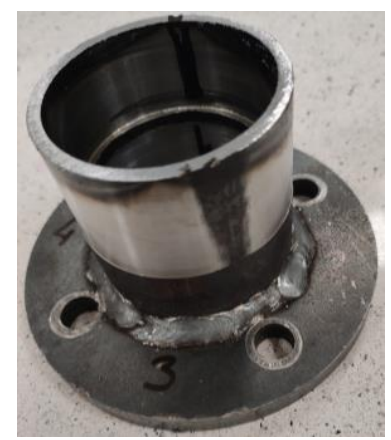

Fig. 21 Example of a welded bearing bush from our own production

Implementation of the proposed solution allowed to obtain measurable benefits in the amount of produced bushs per hour. The production of bushs by hand was approximately 1.5 minutes/piece which was 40 pieces per hour. Stamping the semi-automatic machine allowed to shorten the total time of production of the bush to $20 \mathrm{sec}-$ onds, which was 180 pieces per hour. Thus, a profit of 4.5 times more than the manual production process was obtained. The increase in production was possible due to the correlation of reducer speed, welding current and welding wire feeding speed. An additional advantage was also the quality of the weld face, which in its present form was equal on its entire circumference, which could not be said about the weld during manual welding, Figs. 16 and 21. 
The previous welding method resulted in random cracking of the welded spot under the plate load. Such places are a clear place of occurrence of the technological notch, which is the source of stress concentration, and as a result of the weld cracking. The occurrence of the mentioned notches is an effect of the lack of uniform crosssection of the weld on its entire circumference, which is shown in Fig. 21.

Unfortunately, due to the pandemic situation on the day of writing this paper, it was not possible to obtain a bush welded with the developed device.

\section{Conclusions}

Based on the conducted tests, the authors can present the following final conclusions:

- The finite element method may be applied for the quantitative assessment of such type of components when the boundary conditions are known.

- The non-destructive tests performed by penetrant method did not reveal any external cracks in the joint area that could result from the load applied.

- The metallographic inspection revealed nonconformities in the form of cracks in the weld cross-section.

- To avoid the occurrence of excessive number of engineering notches resulting from welding of detail parts, the production process should be optimized as regards the application of dedicated welding tools.

- Further activities shall be conducted to select the engineering parameters of machining to obtain the most beneficial quality of the weld during the shortest production time.

- The application of the earlier-mentioned semi-automatic welder allowed, in the real conditions, reducing the fabrication time from 1.5 minute to 20 seconds for the unitary production. For the series production, the proper manner of semi-product preparation within the welding seat must be considered.

- Both the loading parameters accepted for tests and the number of cycles were selected based on the data obtained from the Henryk Batyra Agricultural Machines company in Lublin, Poland.

- Since the tests were related to industrial use, the described tests were discontinued due to the prevailing pandemic. As the next step, the tests will be carried out with the developed welding equipment in order to improve the quality of the weld and the influence of technological parameters on obtaining the most advantageous welded joint.

\section{References}

1. Talarczyk, W. 2007. Konstrukcja i działanie kompaktowej brony talerzowej, Technika Rolnicza Ogrodnicza Leśna 2: 11-13.

2. https://www.mascus.pl/rolnictwo/uzywane-brony-talerzowe (accessed on 2408 2020).

3. http://henryk.com.pl (accessed on 2408 2020).

4. Szydło, K.; Lonkwic, P.; Molski, Sz. 2016. The impact of progressive gear geometry on the breaking distance length under changeable operating condition, Advanced in Sciences and Technology 10(29): 161-167.

5. Krakowski, T.; Przystupa, K.; Ruta, H.; Lonkwic, P. 2020. Case study of support frame optimization using a distant load, Sustainbility 12(3). https://doi.org/10.3390/su12030974.

6. Gontarz, A.; Pater, Z.; Tofil, A. 2011. Numerical analysis of unconventional forging process of hollowed shaft from Ti-6AI-4V alloy, Journal of Shanghai Jiaotong University (Science)16(2): 157-161.

7. Meneghetti, G.; Campagnolo, A. 2020. State-of-theart review of peak stress method for fatigue strength assessment of welded joints, International Journal of Fatigue 139.

8. https://ama-parts.pl/piasty-do-agregatow-uprawowych157814-piasta-talerza-bezobslugowa-typ-skf-4-otworowa-bez-srub.html (accessed on 0712 2020).

9. PN EN 10025:2002 (PL). Non-alloy structural steel for hot-rolled products.

10. PN EN ISO 3452-1:2013-08 (EN). Non-destructive testing - Penetration testing - Part 1: General principles.

11. PN EN ISO 3452-3:2014-02 (EN). Non-destructive testing - Penetration testing - Part 1: Reference samples.

12. PN EN ISO 23277:2015-05 (EN). Non-destructive testing of welds - Penetration testing of welds - Acceptance level.

P. Lonkwic, I. Usydus, A. Tofil, T. Krakowski, H. Ruta, D. Pienik

\section{CASE STUDY ON NUMERICAL OPTIMIZATION OF A DISC BUSH IN THE DISC HARROW AND WELDING PROCESSES}

S u m m a r y

The optimization of production processes in companies comes down to two main measures influencing the economic factor. The first one is the reduction of interval micro-periods between operations, and the second is to use post-production waste as much as possible. These treatments apply to virtually all industries regardless of the final product effect. This article describes the application of a special welding device for welding the workpiece with a bush type, designed for fixing the plate in the plate gun. As a result of its application, a significant reduction of time needed to produce one bush has been achieved, and thus the amount of time in a unit of time has been increased. As part of the implementation work, the bush design changes were also made, which made it possible to reduce post-production waste not suitable for current production, but allowing its use for other purposes. The results of the work were implemented in the company producing agricultural machinery in Lublin.

Keywords: disc harrow, optimization, FEM, production process, welding process, agricultural machinery.

Received January 13, 2021 Accepted December 07, 2021 